\title{
ENVIRONMENTAL FACTORS AFFECTING THE SPATIOTEMPORAL DISTRIBUTION OF DECAPTERUS MARUADSI IN THE WESTERN GUANGDONG WATERS, CHINA
}

\author{
YU, J. ${ }^{1}-$ LIU, Z.-N. ${ }^{1,2}-$ CHEN, P.-M. ${ }^{1}-$ YAO, L.-J. ${ }^{3 *}$ \\ ${ }^{1}$ South China Sea Fisheries Research Institute, Chinese Academy of Fishery \\ Sciences/Guangdong Provincial Key Laboratory of Fishery Ecology and Environment/Scientific \\ Observing and Experimental Station of South China Sea Fishery Resources and Environment, \\ Ministry of Agriculture and Rural Affairs/Guangdong Engineering Technology Research Center \\ of Marine Recreational Fishery/Key Laboratory of Marine Ranching Technology, CAFS, \\ Guangzhou 510300, China \\ ${ }^{2}$ College of Marine Science, Shanghai Ocean University, Shanghai 201306, China \\ ${ }^{3}$ Department of Optoelectronic Engineering, College of Science and Engineering, Jinan \\ University, Guangzhou 510632, China \\ *Corresponding author \\ e-mail: constancecarson15@gmail.com
}

(Received $8^{\text {th }}$ Mar 2019; accepted 21 $1^{\text {st }}$ May 2019)

\begin{abstract}
Decapterus maruadsi is a small pelagic fish and is of great significance to the ecosystems in the northern South China Sea. We collected and analyzed the data recorded by the fishing vessels in the western Guangdong waters in winter and summer and remote sensing data including sea surface temperature (SST), chlorophyll a concentration (Chl a) and sea level anomalies (SLA) from 2011 to 2015, using generalized additive model (GAM). Results showed that the catch per unit effort (CPUE) of $D$. maruadsi in the western Guangdong waters had a significant positive linear correlation with longitude, and the $D$. maruadsi populations were concentrated in the east of the study area. The total explanation of D. maruadsi CPUE in GAMs was $47.40 \%$, among which, the factors year, month, lunar phase, latitude, Chl a, SLA and water depth explained $9.30 \%, 13.50 \%, 6.50 \%, 1.90 \%, 1.70 \%, 4.60 \%$, and $9.90 \%$, respectively. The D. maruadsi populations in the study were concentrated in the area of latitude $21^{\circ} \mathrm{N}$, Chl a $0.1-0.5 \mathrm{mg} \cdot \mathrm{m}^{-3}$, SLA $-0.05 \mathrm{~m}$ and water depth $80 \mathrm{~m}$. Results of this work will help in understanding the environmental factors affecting D. maruadsi distribution in the western Guangdong waters.
\end{abstract}

Keywords: generalized additive model, environmental factors, habitat suitability index (HSI), fisheries, main spawning habitats

\section{Introduction}

Decapterus maruadsi, a pelagic fish in the family Carangidae (Perciformes), lives in warm waters, and is widely distributed along the coasts of Southeast China (Deng et al., 1991). It is one of the major species captured by pelagic trawls and light luring seine fishing vessels (Zheng et al., 2014; Thanh and Do, 2018). D. maruadsi has a short lifespan and fast growth and reproduction rate, and as an R-selected species, it is susceptible to fishing intensity and marine environment (Chen et al., 2003; Dai, 2017; Austin et al., 2018). The populations of D. maruadsi in the northern South China Sea shifted towards younger age and smaller size due to overfishing since the 1990s ( $\mathrm{Lu}$, 2000; Chen and Qiu, 2009). But the D. maruadsi resource is beginning to recover due to summer fishing moratorium and other fishery industry restructuring policies in recent years (Chen et al., 2010; Geng et al., 2018; Abija and Nwankwoala, 2018). As a small 
pelagic fish, D. maruadsi has an important impact on the ecosystem output of the northern South China Sea (Chen and Qi, 2009). The sea area off western Guangdong is one of the main spawning habitats for D. maruadsi in the northern South China Sea (Chen et al., 2003), so it is of great significance to investigate the temporal and spatial distribution of this species in this area. At present, the existing studies on D. maruadsi are mostly focused on its biology (Jiang, 2012; Huang, 1995; Da, 2017), resource assessment (Chen and Qiu, 2003; Jamil et al., 2018), etc. Acoustic assessments indicate that carangid fish such as D. maruadsi along the east coast of Peninsular Malaysia are concentrated at 40-60 m below the ocean surface (Hashim, 2017; Tao, 2018). The studies that assessed the relationship between $D$. maruadsi fisheries and environmental factors in the northern South China Sea in different seasons based on the habitat suitability index (HSI) model indicated that chlorophyll a ( $\mathrm{Chl}$ a) concentration is the determinant of the distribution of D. maruadsi fisheries in spring. In recent years, due to the increase in offshore fishing intensity, changes in ecological environment and climate, the resource stock and spatial distribution of many marine species have changed, which has a profound impact on fish habitats and ecosystems. Therefore, evaluating the correlation between $D$. maruadsi distribution and marine environmental factors in western Guangdong is important for the sustainable development of fisheries.

The relationship between fishery resources and marine environment is very complicated, as it is non-linear and non-additive (Stenseth et al., 2002, 2004; Dingstor et al., 2007; Tianlei, 2019), and the use of different observational scales can cause large differences in results (Fauchald et al., 2000). Therefore, it is crucial to choose a suitable method for quantitative analysis of the relationship between fishery resources and the marine environment. As the nonparametric extensions of generalized linear models (GLMs), generalized additive models (GAMs) provide flexible method for uncovering the nonlinear relationship between response and predictor variables (Hastie and Tibshirani, 1990; Jegatheesan and Zakaria, 2018), and thus are suitable for exploring the nonlinear relationship between fishery resources and marine environment (Stoner, 2001; Agenbag, 2003). GAMs not only can be used for different species or different seas, but also can be combined with a variety of environmental factors to better reveal the relationship between environmental factors and the variation, spatial distribution, temporal distribution of fishery resources (Venables et al., 2004; La et al., 2016; Bacha et al., 2017). The studies based on GAMs have shown that zooplankton biomass and the location of oceanic fronts have an impact on the distribution of Clupea harengus in the vicinity of the Shetland Islands (Maravelias et al., 1997). The spatial distribution of Loligo spp. and Tachysurus in the Arabian Sea was well predicted based on the data of sea surface temperature (SST), chlorophyll a (Chl a) concentration, photosynthetically active radiation (PRA) and sea level anomalies (SLA) in the study of Solanki (2017). The interaction between upwelling index, year and latitude had a great influence on the spatial distribution of sardines in Mauritanian waters (Bacha et al., 2017; Abdullah and Rahim, 2018). Wang et al. (2018) reported that prey density, water depth, bottom water temperature and distance to shore had a great influence on the distribution of Chinese white dolphin in western Pearl River Estuary.

In this study, generalized additive models (GAMs) were used to quantitatively analyze the main environmental factors affecting the spatiotemporal distribution of $D$. maruadsi, and to explore the formation mechanism of D. maruadsi fishery in the western Guangdong waters, and to provide a theoretical basis for fishery management and marine protected area planning under climate changes. 


\section{Materials and methods}

\section{Data collection}

\section{Fishery data}

The data of $D$. maruadsi resource were from the observational records of large-scale light-luring seine fishing vessels in western Guangdong waters $\left(19.75^{\circ}\right.$ to $21.75^{\circ} \mathrm{N}$, $111.25^{\circ} \mathrm{E}$ to $113.75^{\circ} \mathrm{E}$ ) in January, February, August and September from 2011 to 2015. The data (including working time, voyage, longitude, latitude and fish catch) were generated at a spatial resolution of $0.5^{\circ} \times 0.5^{\circ}$ in latitude and longitude (one fishing area), and summarized by day (Fig. 1).

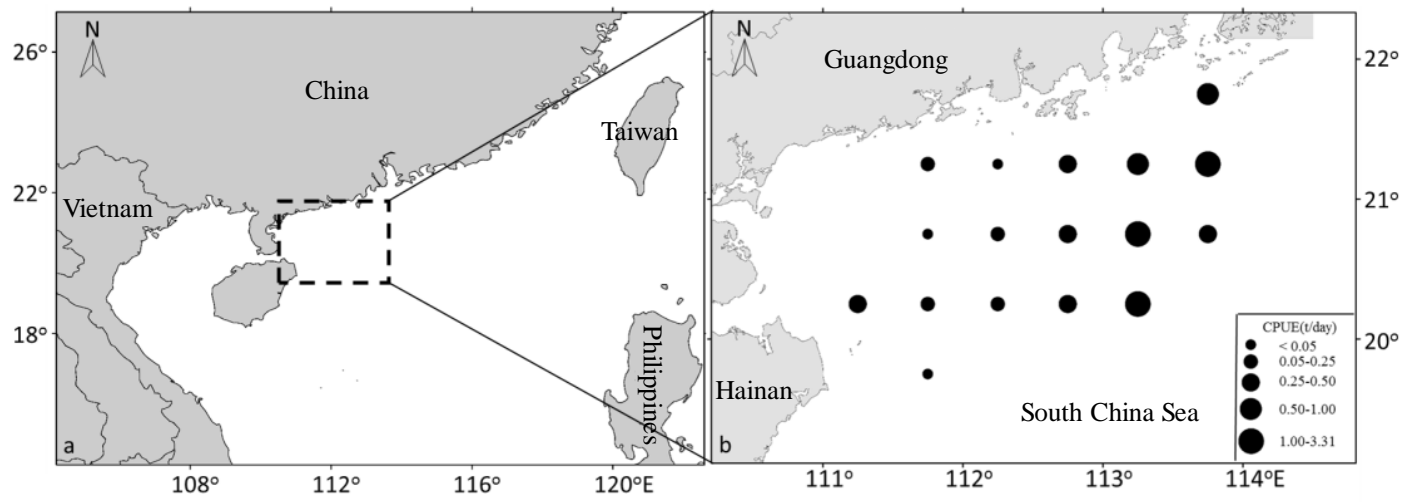

Figure1. Distribution of D. maruadsi CPUE in western Guangdong waters

\section{Environmental data}

The remote sensing data including chlorophyll a concentration (Chl a), sea surface temperature (SST) and sea level anomalies (SLA) were used in this study. Among them, Chl a and SST were from MODIS Aqua Level 3 data products (https://oceancolor.gsfc.nasa.gov), with a temporal resolution of one day and a spatial resolution of $4 \mathrm{~km}$. SLA data were from CTOH/LEGOS website (https://www.aviso.altimetry.fr/en/home.html) with a temporal resolution of one day and a spatial resolution of $0.25^{\circ}$. Water depth data were acquired from Google Earth, with a spatial resolution of $70 \mathrm{~m}$ (Jaimes, 2017).

\section{Data processing}

CPUE (catch per unit effort) calculation (Campbel, 2004)

$$
\text { CPUE }=\frac{c}{f}
$$

where, CPUE is the average daily D. maruadsi catch by a vessel (unit: tons per day), c is daily $D$. maruadsi catch in a $0.5^{\circ} \times 0.5^{\circ}$ fishing grid (unit: tons), $f$ is the number of operations in a $0.5^{\circ} \times 0.5^{\circ}$ fishing grid (days). 
Remote sensing data fusion (Fu et al., 2009)

The remote sensing data (Chl, SST and SLA) of the study area were extracted and merged using the formula as follows:

$$
\text { Average }_{j}=\frac{\sum_{i=1}^{M R} \operatorname{Value}^{(i)_{j}}}{m}
$$

where, Average $_{j}$ is the mean value of fused environmental data (Chl, SST and SLA) in fishing grid $j, j$ is a $0.5^{\circ} \times 0.5^{\circ}$ fishing grid, $m$ is the number of pixels of environmental data (Chl, SST, SLA) in fishing grid $j$, Value $(i)$ is the value of a single pixel in fishing area $j$.

\section{GAM analysis}

Generalized additive models (GAM) focus on exploring data nonparametrically, compared to generalized linear models (Feng, 2007; Sudhakaran et al., 2018). In order to avoid excessive computation and over-fitting, the linear correlation between $D$. maruadsi CPUE and each predictor variable was measured according to Pearson correlation coefficient $R$ before GAM was constructed (Li, 2007; Le, 2017). When $R>0.5$, the predictor variable has a linear relationship with $D$. maruadsi CPUE, and should be removed from the model. The $\mathrm{R}$ mgcv package was used to fit the GAM (Wood, 2004, 2011). The general form of the model can be written as:

$$
\mathrm{g}(\mu)=\beta+f_{1}\left(\mathrm{x}_{1}\right)+\cdots+f_{\mathrm{i}}\left(\mathrm{x}_{\mathrm{i}}\right)+\varepsilon
$$

where $g(\mu)$ is the link function, which is the logarithm of CPUE $+1 ; \beta$ is the intercept term; $f$ is a smooth function, $i$ is the number of predictor variables, $\varepsilon$ is the error term. The GAM procedure uses smoothing splines $\mathrm{s}($ ).

\section{Diagnosis of GAM}

The predictor variables influencing $D$. maruadsi CPUE that should be incorporated into the model were identified applying a stepwise GAM and according to Akaike Information Criterion (AIC) (Shih, 2014; Franco et al., 2018). Models were built by adding in new terms and seeing how much they improved the fit, and by dropping terms that did not degrade the fit significantly. The influence of the predictors was assessed via $F$-test and chi-square test (Quinn and Deriso, 1999). AIC was calculated as follows (Venables, 2004):

$$
\mathrm{AIC}=\theta+2 \mathrm{~d} f \delta
$$

where $\theta$ is the deviance, $\mathrm{d} f$ is the effective degree of freedom, and $\delta$ is the variance.

\section{Violin plot}

A violin plot, similar to a box plot with a rotated kernel density plot on each side, simultaneously reflects the statistical features (maximum, minimum, median, and upper and lower quartiles) and distribution of a set of data (Hintze, 1998). The violin plot was made using the ggplot2 package in $\mathrm{R}$ software from $D$. maruadsi CPUE in winters 
(January and February) and summers (August and September). Since the average CPUE differed greatly, the ordinate was scaled logarithmically. Then the violin plot was used to analyze the difference in D. maruadsi CPUE between winters and summers in western Guangdong waters (Cortez, 2016).

\section{Results}

\section{Linear correlation analysis between D. maruadsi CPUE and the influencing factors}

Pearson correlation analysis on D. maruadsi CPUE and the factors influencing it including year, month, lunar phase, longitude (Lon), latitude (Lat), SST, Chl a, SLA and water depth (Table 1) showed that seven of the factors (month, lunar phase, longitude, latitude, SST, Chl a, SLA and depth) were significantly correlated with $D$. maruadsi CPUE $(P<0.05)$, and the correlation coefficient between longitude and CPUE was greater than $0.5(R>0.5)$, indicating that longitude had a strong positive linear correlation with $D$. maruadsi CPUE. Therefore, longitude was removed from the GAM.

Table 1. Pearson correlation coefficient of Decapterus maruadsi CPUE and Impact factors

\begin{tabular}{c|c|c}
\hline Factors & Cor & P-value \\
\hline Year & -0.067 & 0.345 \\
Month & 0.292 & $2.514^{*} 10^{-5}$ \\
Lunar phase & -0.146 & 0.038 \\
Lon & 0.535 & $2.678^{*} 10^{-16}$ \\
Lat & 0.205 & 0.003 \\
SST & 0.261 & $1.830^{*} 10^{-4}$ \\
Chl a & -0.167 & 0.018 \\
SLA & -0.178 & 0.012 \\
Depth & -0.163 & 0.021 \\
\hline
\end{tabular}

Analysis of longitudinal distribution of D. maruadsi CPUE (Fig. 2) revealed that the maximum values of D. maruadsi CPUE within longitude $115.25^{\circ} \mathrm{E}-113.75^{\circ} \mathrm{E}$ were $0.56 \mathrm{t} / \mathrm{d}, 1.00 \mathrm{t} / \mathrm{d}, 1.00 \mathrm{t} / \mathrm{d}, 3.00 \mathrm{t} / \mathrm{d}, 30.20 \mathrm{t} / \mathrm{d}$ and $18.00 \mathrm{t} / \mathrm{d}$, respectively. The upper quartile of $D$. maruadsi CPUE increased with longitude increasing from $112.25^{\circ} \mathrm{E}$ to $113.75^{\circ} \mathrm{E}$. The median value and lower quartile of $D$. maruadsi CPUE also increased with longitude increasing from $111.75^{\circ} \mathrm{E}$ to $113.75^{\circ} \mathrm{E}$. There were fewest data at $111.25^{\circ} \mathrm{E}$ and most data $113.25^{\circ} \mathrm{E}$. To sum up, D. maruadsi CPUE value showed a general decreasing trend from east to west in the study area, and the high CPUE values were concentrated within $113.25^{\circ} \mathrm{E}-113.75^{\circ} \mathrm{E}$.

\section{Environmental effects on D. maruadsi CPUE based on GAM analysis}

The GAM was built by adding in the temporal, spatial and environmental factors stepwise and seeing how much they improved the fit. The temporal, spatial and environmental variables included in the model were year, month, lunar phase, latitude, Chl a, SLA and depth (Table 2). The GAM could explain $47.40 \%$ of the variability in D. maruadsi CPUE in total, and the residual degrees of freedom was 185.23. 


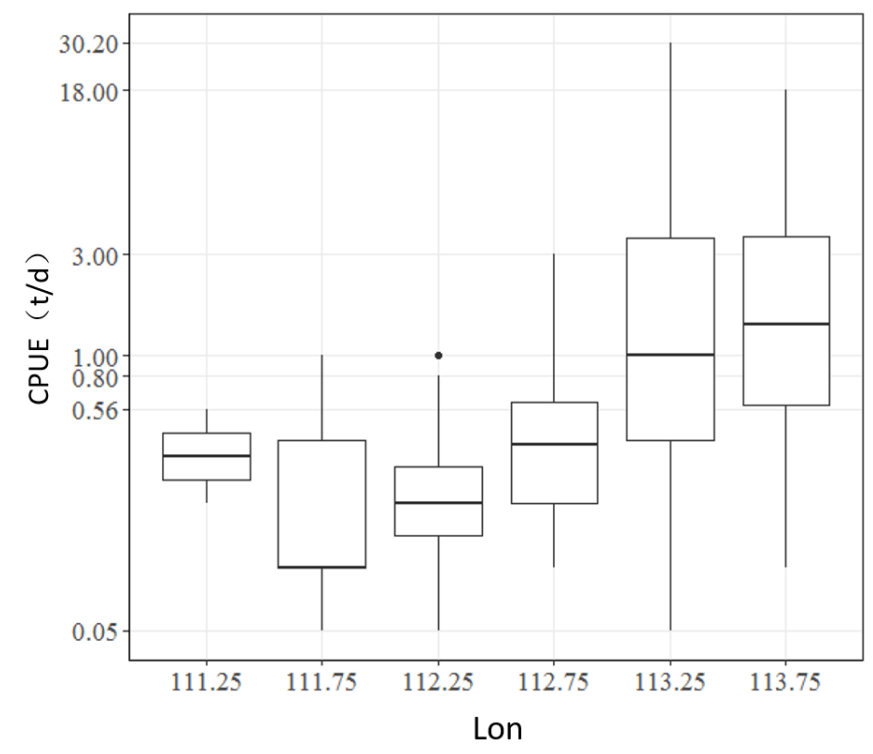

Figure 2. Box plot of longitudinal distribution of D. maruadsi CPUE

Table 2. Generalized additive models (GAMs) fitted to D. maruadsi CPUE and analysis of deviance

\begin{tabular}{|c|c|c|c|}
\hline Factors & $\begin{array}{c}\text { Residual } \\
\text { degree of } \\
\text { freedom }\end{array}$ & $\begin{array}{c}\text { AIC } \\
\text { value }\end{array}$ & $\begin{array}{c}\text { Cumulative } \\
\text { of deviance } \\
\text { explained }\end{array}$ \\
\hline $\log ($ CPUE +1$)=$ NULL & 200.00 & 16.34 & 0.00 \\
\hline $\log ($ CPUE +1$)=s($ Year $)$ & 196.28 & 4.16 & $9.30 \%$ \\
\hline $\log ($ CPUE +1$)=s($ Year $)+s($ Month $)$ & 193.73 & -23.09 & $22.80 \%$ \\
\hline $\log ($ CPUE +1$)=s($ Year $)+s($ Month $)+s($ Lunar phase $)$ & 191.87 & -37.14 & $29.30 \%$ \\
\hline $\begin{array}{c}\log (\text { CPUE }+1)=s(\text { Year })+s(\text { Month })+s(\text { Lunar } \\
\text { phase })+s(\text { Lat })\end{array}$ & 191.08 & -40.88 & $31.20 \%$ \\
\hline $\begin{array}{c}\log (\text { CPUE }+1)=s(\text { Year })+s(\text { Month })+s(\text { Lunar } \\
\text { phase })+s(\text { Lat })+s(\text { Chl a })\end{array}$ & 190.24 & -44.22 & $32.90 \%$ \\
\hline $\begin{array}{c}\log (\text { CPUE }+1)=s(\text { Year })+s(\text { Month })+s(\text { Lunar } \\
\text { phase })+s(\text { Lat })+s(\text { Chl a })+s(\text { SLA })\end{array}$ & 190.24 & -54.73 & $37.50 \%$ \\
\hline $\begin{array}{l}\log (\text { CPUE }+1)=s(\text { Year })+s(\text { Month })+s(\text { Lunar } \\
\text { phase })+s(\text { Lat })+s(\text { Chl a })+s(\text { SLA })+s(\text { Depth })\end{array}$ & 185.23 & -83.23 & $47.40 \%$ \\
\hline $\begin{array}{c}\log (\text { CPUE }+1)=s(\text { Year })+s(\text { Month })+s(\text { Lunar } \\
\text { phase })+s(\text { Lat })+s(\text { Chl a) }+\mathrm{s}(\text { SLA })+s(\text { Depth })+s(\text { SST })\end{array}$ & 184.21 & -82.33 & $47.70 \%$ \\
\hline
\end{tabular}

The contribution of each factor included in GAMs to D. maruadsi CPUE indicated their influence on D. maruadsi CPUE (Table 3). Among them, the most influential factor was month, which explained $13.50 \%$ of the variability in D. maruadsi CPUE, followed by depth, year, lunar phase, SLA, latitude, Chl a, which explained $9.9 \%$, $9.30 \%, 6.50 \%, 4.60 \%, 1.90 \%$, and $1.70 \%$ of the variability in D. maruadsi CPUE respectively. The $F$ test and Chi-squared test showed that after SST was added into the model, it did not degrade the fit significantly $(P>0.05)$, while $A I C$ value increased, suggesting that SST had no significant effect on D. maruadsi CPUE, so it was removed from the model. 
Table 3. Statistical significance and contribution of the factors in GAM

\begin{tabular}{c|c|c|c|c|c}
\hline Factors & $\begin{array}{c}\text { Degree of } \\
\text { freedom }\end{array}$ & P-value & F-test & Chi-square test & $\begin{array}{c}\text { Contribution of } \\
\text { selected variables }\end{array}$ \\
\hline Year & 3.69 & $1.35^{*} 10^{-3}$ & $6.71 * 10^{-4}$ & $4.51^{*} 10^{-4}$ & $9.30 \%$ \\
Month & 1.00 & $1.92 * 10^{-6}$ & $6.02 * 10^{-7}$ & $1.70^{*} 10^{-7}$ & $13.50 \%$ \\
Lunar phase & 1.91 & $2.80 * 10^{-4}$ & $1.88 * 10^{-4}$ & $1.27 * 10^{-4}$ & $6.50 \%$ \\
Lat & 1.72 & $1.30 * 10^{-2}$ & 0.02 & 0.02 & $1.90 \%$ \\
Chl a & 1.00 & $1.76 * 10^{-2}$ & 0.03 & 0.03 & $1.70 \%$ \\
SLA & 2.76 & $1.47 * 10^{-3}$ & $5.47 * 10^{-4}$ & $4.20^{*} 10^{-4}$ & $4.60 \%$ \\
Depth & 2.71 & $7.32 * 10^{-7}$ & 1.616 & $4.31 * 10^{-7}$ & $9.90 \%$ \\
SST & 1.00 & 0.317 & 0.32 & 0.32 & $0.30 \%$ \\
\hline
\end{tabular}

Relationship between D. maruadsi CPUE and the influencing factors (Fig. 3). Among all temporal factors, the year factor showed a positive effect in 2011-2013 and 2014-2015 (Fig. 3a) and a negative effect in 2013-2014, with no significant change in the confidence interval (Fig. 3b). From January to February, and from August to September, D. maruadsi CPUE increased monotonously over time; the width of the confidence interval decreased between different seasons (from February to August), and increased within the same seasons (January to February, August to September). $D$. maruadsi CPUE monotonously decreased with lunar phase changing from 1 to 15 , and monotonously increased with lunar phase changing from 15 to 30 (Fig. 3c), with no significant change in the confidence interval.
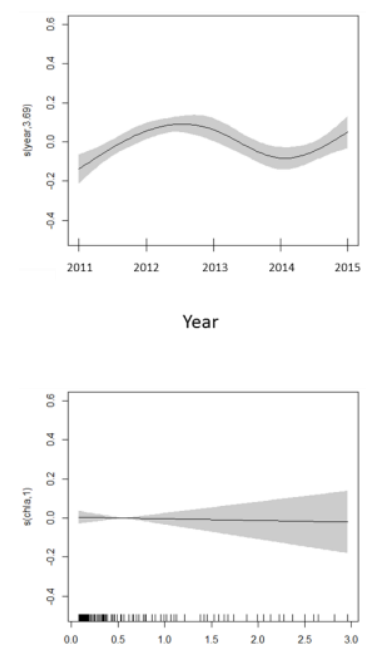

$\mathrm{Chl} \mathrm{a}$

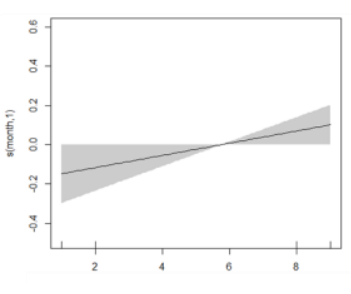

Month

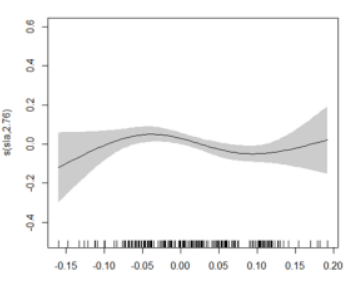

SLA

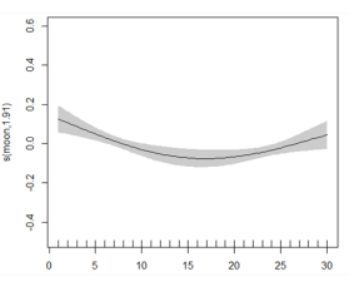

Lunar phase

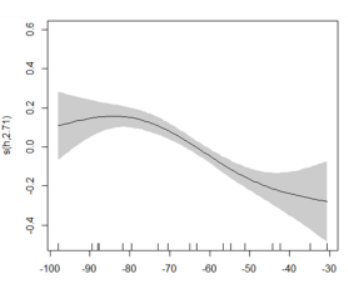

Depth

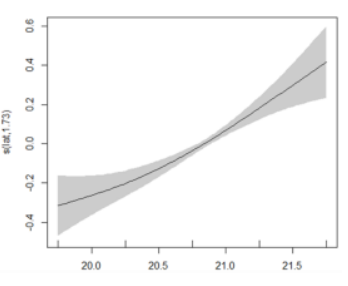

Lat

Figure 3. Effects of different factors on D. CPUE from GAM analysis. The shadow area indicates the $95 \%$ confidence intervals. Rug plots on the $x$-axis indicate data density

D. maruadsi CPUE increased monotonically with latitude increasing from $20^{\circ} \mathrm{N}$ to $21.5^{\circ} \mathrm{N}$ (Fig. $3 d$ ). The width of the confidence interval decreased within $20.5^{\circ} \mathrm{N}-$ $21.0^{\circ} \mathrm{N}$, suggesting increased reliability of the estimation. The width of the confidence interval increased within $20.0^{\circ} \mathrm{N}-20.5^{\circ} \mathrm{N}$ and $21.0^{\circ} \mathrm{N}-21.5^{\circ} \mathrm{N}$ suggesting decreased reliability of the estimation. 
D. maruadsi CPUE changed little with Chl a increasing (Fig. 3e). The data were concentrated within $\mathrm{Chl}$ a range of $0.1-0.5 \mathrm{mg} \cdot \mathrm{m}^{-3}$, and the narrow confidence interval indicated high reliability of the estimation. With $\mathrm{Chl}$ a increasing in the range of 0.5$3.0 \mathrm{mg} \cdot \mathrm{m}^{-3}$, the amount of data decreased, the width of confidence interval increased, indicating the reliability of the estimation decreased. It showed the effect of SLA on $D$. maruadsi CPUE (Fig. 3f). With SLA increasing from -0.15 to $-0.05 \mathrm{~m}$, D. maruadsi CPUE increased, and the width of confidence interval decreased. As SLA increased from -0.05 to $0.10 \mathrm{~m}, D$. maruadsi CPUE decreased, the confidence interval became narrower, indicating the reliability of the estimation increased. As SLA increased from 0.10 to $0.20 \mathrm{~m}, D$. maruadsi CPUE increased again, while the confidence interval became broader, and the reliability of the estimation decreased. The data were concentrated within SLA range of -0.8 to $0.13 \mathrm{~m}$. It showed the effect of water depth on D. maruadsi CPUE (Fig. 3g). In detail, D. maruadsi CPUE increased with depth increasing from 30 to $80 \mathrm{~m}$, while the width of confidence interval increased, indicating that the reliability of the estimation increased. With water depth increasing from 80 to $100 \mathrm{~m}$, D. maruadsi CPUE declined, while the width of confidence interval increased, indicating that the reliability of the estimation reduced.

\section{Seasonal variation in D. maruadsi CPUE}

According to GAM analysis, the effect of the month factor which was most influential to $D$. maruadsi CPUE was further analyzed. The fishing vessels were operated in the sea area within $19.75^{\circ}-21.75^{\circ} \mathrm{N}$ and $111.25^{\circ}-113.75^{\circ} \mathrm{E}$ in January, February, August and September every year. Our data revealed that D. maruadsi CPUE was high in summer, with a maximum value of $18.00 \mathrm{t} / \mathrm{d}$, a median value of $1.28 \mathrm{t} / \mathrm{d}$, a minimum value of $0.00 \mathrm{t} / \mathrm{d}$, and the abnormally high value in summer was $30.20 \mathrm{t} / \mathrm{d}$. $D$. maruadsi CPUE was low in winter, with a maximum value of $1.25 \mathrm{t} / \mathrm{d}$, a median of $0.20 \mathrm{t} / \mathrm{d}$, and a minimum value of $0.00 \mathrm{t} / \mathrm{d}$. Comparing the kernel density distribution plots of D. maruadsi CPUE between summer and winter, we found that the distribution of D. maruadsi CPUE in summer was discrete, with a peak value around 0.60 , and that in winter was concentrated, with a peak value around 0.20. All the maximum value, upper quartile, median, and lower quartile of $D$. maruadsi CPUE in summer were higher than in winter (Fig. 4).

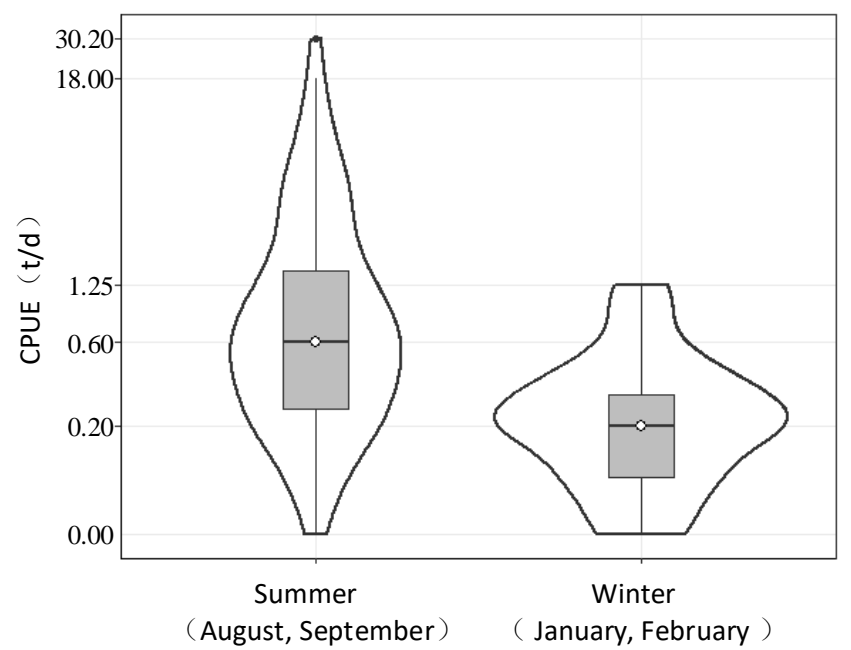

Figure 4. Violin plot of CPUE distribution of Decapterus maruadsi in summer and winter 


\section{Discussion}

\section{Relationship between D. maruadsi CPUE and temporal/spatial factors}

GAMs analyze the relationship between response and predictor variables based on data model. They possess obvious advantages in analyzing the highly nonlinear and non-monotonic relationship between response and predictor variables, and can be used to reveal the unknown ecological relationships in fishery (Hastie et al., 1999; La et al., 2016; Bacha et al., 2017). Among all the factors included in GAM, the month factor made the greatest contribution to the GAM, up to $13.50 \%$ (Table 3). There was an obvious seasonal variation in D. maruadsi resources in western Guangdong waters, and its CPUE was higher in summer (August and September) than in winter (January and February) (Fig. 3b). Studies have shown that the spawning period of $D$. maruadsi begins at the end of winter and ends in summer (Chen et al., 2003; Wu, 2000). Previous studies on D. maruadsi in the Beibu Gulf and the Taiwan Strait indicates that summer is an important season for $D$. maruadsi to fatten up (Huang, 1995; Yang, 2016). D. maruadsi populations are able to increase during summer fishing moratorium (SFM) in June and July, and then gradually decrease from August to November due to the continuous high-intensity fishing in this period, resulting in significant difference in $D$. maruadsi CPUE between winter and summer.

The year factor explained $9.30 \%$ of the variability in D. maruadsi CPUE (Table 3). D. maruadsi CPUE fluctuated during 2011-2015 (Fig. 3a), and the decrease in 2014 was probably due to the unusually late summer monsoon season in the South China Sea in this year (Yuan, 2014). As an R-selected species, it is susceptible to environmental influence (Chen et al., 2003; Yan et al., 1987). The reduced fishing intensity during summer moratorium from June to July (Zhu, 2009; Qu, 2018), and the increased primary productivity caused by the upwelling in western Guangdong waters (Song, 2012) provide favorable conditions for the replenishment of D. maruadsi resources. It is widely accepted that summer winds may be the reason for the strong upwellings in the study area from June to July (Xie, 2016). The summer monsoon in the South China Sea in 2014 started unusually late, which might delay the occurrence of upwelling in this area, as a result, the D. maruadsi resources were not sufficiently replenished. In 2015, the summer monsoon in South China Sea occurred at the usual time (Si et al., 2016), and thus the D. maruadsi resources were able to recover during moratorium, so its CPUE in 2015 was higher than in 2014.

Lunar phase explained $6.50 \%$ of the deviance of the model (Table 3). The relationship between $D$. maruadsi CPUE and lunar phase was represented by an inverted U-shaped curve, with the minimum CPUE value at lunar phase 15 (Fig. 3c), which might be caused by the light luring seine used by the vessels. The moon is at its brightest when full in a month, and the moonlight lowers the attractiveness of light luring seines to cephalopods (Chen et al., 2006; Yan, 2015). As the major catch of light luring seine fishing in western Guangdong waters (Yang et al., 2009), similar results were obtained in $D$. maruadsi in our study. In addition to the influence of moonlight intensity, whether the changes in the marine environment caused by lunar phase have an impact on D. maruadsi CPUE needs to be further studied.

Correlation analysis indicated that there was a positive linear correlation between longitude and D. maruadsi CPUE in western Guangdong waters (Table 1). The violin plot (Fig. 2) showed that the maximum value, median value, and the amount of data of D. maruadsi CPUE were all higher at longitude $113.25^{\circ} \mathrm{E}-113.75^{\circ} \mathrm{E}$. GAM analysis 
showed that latitude and D. maruadsi CPUE had a high positive correlation near longitude $21^{\circ} \mathrm{N}$ (Fig. 3d). D. maruadsi tends to spawn in the areas where seawater is diluted by fresh water, and the spawning season lasts for a long period until the end of summer (Chen et al., 2003; Zhu, 1984). Therefore, D. maruadsi population tends to concentrate in the Pearl River estuary in winter and summer. The decreased water depth along coasts may be the factor restricting the positive effect of latitude, increasing the width of confidence interval north of $21^{\circ} \mathrm{N}$, and reducing the reliability of the estimation.

\section{Relationship between D. maruadsi CPUE and environmental factors}

Among the environmental factors, water depth was the most influential to GAM, and it explained $9.90 \%$ of the deviance (Table 3). In detail, D. maruadsi CPUE increased monotonously with depth increasing from 30 to $80 \mathrm{~m}$, and the reliability of the estimation was higher at depth 50-80 m. With further increase in water depth, $D$. maruadsi CPUE declined monotonously (Fig. 3g). D. maruadsi is a pelagic fish (Deng, 1991). Acoustic assessments indicate that three carangid species including $D$. maruadsi along the east coast of Peninsular Malaysia are concentrated at depth of 40-60 m, and their density is 0 when water depth exceeds $80 \mathrm{~m}$. The depth of study area is about 0 $200 \mathrm{~m}$. While some researchers believe that $D$. maruadsi in this sea area lives at or near the bottom of the sea (Fan, 2018). The GAMs showed that in western Guangdong waters, the high CPUE values of $D$. maruadsi appeared at about $80 \mathrm{~m}$, which might have been affected by light luring seines.

SLA explained $4.6 \%$ of the total deviance (Table 3). The positive effect of SLA on D. maruadsi CPUE peaked at SLA around $-0.05 \mathrm{~m}$ (Fig. $3 f$ ), which may be related to oceanic currents (such as eddies, upwelling) in this area. Remote sensing data about sea surface height such as SLA and sea surface height anomaly (SSHA) are the indicators of oceanic currents and density stratification of seawater (Thomas, 2012), and are widely used for eddy identification (Wang, 2015; Yi, 2014; Zhan, 2014). Eddies regulates SST, SSS, and Chl a by a complicated mechanism (Chelton, 2011; Schütte, 2016; He, 2016). The center of anticyclonic eddies in the northeastern Atlantic is characterized by a negative SLA value and a reduced SST and SSS (Schütte, 2016). Along the coasts of the southwest Indian Ocean, the cold eddies have a negative SSHA value at their center, and stir up nutrients from the bottom, resulting in an elevation in $\mathrm{Chl}$ a. In the northern South China Sea, the positive effect of eddies on $\mathrm{Chl}$ a is stronger than the negative effect of anticyclonic eddies. And the eddies in the northern South China Sea increased seawater $\mathrm{Chl}$ a and promoted the transport of $\mathrm{Chl}$ a along longitude. In addition, SLA in upwelling region also exhibits a certain pattern. In West Africa, the upwelling center has a negative SLA, decreased SST and elevated Chl a (Nieto, 2017). The eastern Hainan-western Guangdong upwelling in the study area increased the $\mathrm{Chl}$ a and primary productivity in the area in summer (Song, 2012; He, 2016). Therefore, it is speculated that the oceanic currents (eddies, upwelling, etc.) at SLA $-0.05 \mathrm{~m}$ provide favorable conditions for $D$. maruadsi, so that the positive effect of SLA on $D$. maruadsi CPUE reaches the maximum level within this SLA range.

No significant correlation between $D$. maruadsi CPUE and Chl a was observed in this study (Fig. 3e), but the data density plot indicated that D. maruadsi CPUE was concentrated at $\mathrm{Chl}$ a ranging from 0.1 to $0.5 \mathrm{mg} \cdot \mathrm{m}^{-3}$, suggesting that $D$. maruadsi tends to live in waters with this range of $\mathrm{Chl}$ a. As an indicator of marine phytoplankton, Chl a has an important impact on fishery distribution. The study on the Pacific saury 
(Cololabis saira) distribution in the northwestern Pacific Ocean based on empirical cumulative distribution function (ECDF) showed that high CPUE occurred when Chl a ranged from 0.4 to $0.6 \mathrm{mg} \cdot \mathrm{m}^{-3}$ (Tseng, 2013). The study on yellowfin tuna (Thunnus albacares) in the western and central Pacific showed that the tuna tends to live in the waters with $\mathrm{Chl}$ a of $0.1-0.6 \mathrm{mg} \cdot \mathrm{m}^{-3}$ (Wang, 2016; Kang, 2018). It has been reported that D. maruadsi in southern Taiwan Strait prefer to live in the waters with Chl a ranging from 0.2 to $1.0 \mathrm{mg} \cdot \mathrm{m}^{-3}(\mathrm{Li}, 2006)$. The data density distribution based on GAM analysis in this study revealed a $\mathrm{Chl}$ a range suitable for $D$. maruadsi in the western Guangdong waters.

\section{Conclusions}

To examine the relative influence of environmental factors on the distribution of $D$. maruadsi, data recorded by the fishing vessels and remote sensing including SST, Chl a and SLA in the western Guangdong waters, were analyzed using GAMs combined with correlation analysis in this study. Results showed that D. maruadsi CPUE in western Guangdong waters had a significant positive linear correlation with longitude, showing a general trend of decreasing from east to west. The final model explained $47.40 \%$ of the variability in D. maruadsi CPUE in total. Among all the factors included in the model, month was most influential to the distribution of $D$. maruadsi, followed by depth, year, lunar phase, SLA and latitude, Chl a and SST. The D. maruadsi resources were concentrated in the areas where the latitude was $21^{\circ} \mathrm{N}$, Chl a ranged from 0.1 to $0.5 \mathrm{mg} \cdot \mathrm{m}^{-3}$, SLA was $-0.05 \mathrm{~m}$ and water depth was $80 \mathrm{~m}$. The fishing method (light luring seines) used in this study might affect the conclusions about the effects of lunar phase and water depth on D. maruadsi CPUE. Therefore, different fishing methods will be used verify the effects of the two factors in the future work.

Acknowledgements. This study was supported by the following funds: (1) Central Public-interest Scientific Institution Basal Research Fund, CAFS (2018HY-ZD0104), (2) National Key R\&D Program of China (2018YFD0900901); (3) Natural Science Foundation of Guangdong Province, China (2018A030313120), (4) State Key Laboratory of Tropical Oceanography, South China Sea Institute of Oceanology, Chinese Academy of Sciences (LTO1806).

\section{REFERENCES}

[1] Abdullah, N. A., Rahim, F. (2018): Distinctiveness and potentials of two flowering roadside hedgerows, Turnera ulmifolia and Melastoma malabathricum as benefecial plants for insects. - Environment \& Ecosystem Science 2(2): 06-10.

[2] Abija, F. A., Nwankwoala, H. O. (2018): Characterization of aquifers in parts of Abia State Southeastern Nigeria. - Earth Sciences Pakistan 2(1): 18-22.

[3] Agenbag, J. J., Richardson, A. J., Demarcq, H. et al. (2003): Estimating environmental preferences of South African pelagic fish species using catch size- and remote sensing data. - Progress in Oceanography 59(2): 275-300.

[4] Austin, O. E., Ebuka, A. O., Zanders, A. C. C., Joseph, I. N. (2018): Seismic analysis of the transgressive systems tracts (TSTS) of the Niger Delta. - Earth Sciences Malaysia 2(2): 16-19.

[5] Bacha, M, Jeyid. M. A., Vantrepotte, V. et al. (2017): Environmental effects on the spatio-temporal patterns of abundance and distribution of Sardina pilchardus and 
sardinella off the Mauritanian coast (North-West Africa). - Fisheries Oceanography 8(5): $12-25$.

[6] Campbell, R. A. (2004): CPUE standardisation and the construction of indices of stock abundance in a spatially varying fishery using general linear models. - Fisheries Research (Amsterdam) 70(2-3): 0-227.

[7] Chelton, D. B., Samelson, R. M. (2011): The influence of nonlinear mesoscale eddies on near-surface oceanic chlorophyll. - Science 334(6054): 328.

[8] Chen, G. B., Qiu, Y. S. (2003): Study on growth, mortality and reasonable utilization of Decapterus maruadsi in northern continental shelf waters of South China Sea. - Journal of Applied of Oceanography 22(4): 457-464.

[9] Chen, G. B., Li, Y. Z., Chen, P. M. A. (2003): study on spawning ground of blue mackerel scad (decapterus maruadsi) in continental shelf waters of Northern South China Sea. - Journal of Tropical Oceanography 22(6): 22-28.

[10] Chen, X. J., Tian, S. Q., Qian, W. G. (2006): Effect of moon phase on the jigging rate of Ommastrephes bartrami in the North Pacific. - Marine Fisheries 28(2): 136-140.

[11] Chen, Z. Z., Qiu, Y. S. (2009): Assessment of the food-web structure, energy flows, and system attribute of northern South China Sea ecosystem. - Acta Ecologica Sinica 30(18): 4855-4865.

[12] Chen, Z. Z., Lin, Z. J., Qiu, Y. S. (2010): Evaluation of sustainability of fisheries resources for South China Sea based on the AHP. - Journal of Natural Resources 25(2): 249-257.

[13] Cortez, A. (2016): 3. Variabilidad espacio temporal de la precipitación en el estado Guárico, Venezuela. - Revista de la Facultad de Agronomia de la Universidad del Zulia 33(3).

[14] Dai, J. G., Chen, Z. Z., Hunag, Z. R., Xu, Y. W., Sun, M. S., Zhang, K., Jiang, Y. E. (2017): Otolith morphology of Decapterus maruadsi in the continental shelf of northern South China Sea. - Journal of Applied of Oceanography 36(3): 417-426.

[15] Deng, J. Y. (1991): Marine Biology. - China Agriculture Press, Beijing.

[16] Dingstor, G. E., Ciannelli, L., Chan, K. S. et al. (2007): Density dependence and density independence during the early life stages of four marine fish stocks. - Ecology 88(3): 625-634.

[17] Fan, J. T., Huang, Z. R., Xu, Y. W., Sun, M. S., Chen, G. B., Chen, Z. Z. (2018): Habitat model analysis for decapterus maruadsi in northern South China Sea based on remote sensing data. - Transactions of Oceanology and Limnology 3: 142-147.

[18] Fauchald, P., Skarsfjord, H., Erikstad, K. E. (2000): Scale-dependent predator-prey interactions: the hierarchical spatial distribution of seabirds and prey. - Ecology 81(3): 773-783.

[19] Franco, G. H., Macancela, N. A., Gavín-Quinchuela, T., Carrión-Mero, P. (2018): Participatory socio-ecological system: Manglaralto-Santa Elena, Ecuador. - Geology, Ecology, and Landscapes 2(4): 303-310.

[20] Fu, D. Y., Pan, D. L., Ding, Y. Z., Zou, J. H. (2009): Quantitative study of effects of the sea chlorophyll-a concentration by typhoon based on remote-sensing. - Acta Oceanologica Sinica 31(3): 46-56.

[21] Geng, P., Zhang, K., Chen, Z. Z. Xu, Y. W., Sun, M. S. (2018): Interannual change in biological traits and exploitation rate of Decapterus maruadsi in Beibu Gulf. - South China Fisheries Science 14(6): 1-9.

[22] Hashim, M., Aziz, M. F. H. A., Hassan, R. B. et al. (2017): Assessing target strength, abundance, and biomass for three commercial pelagic fish species along the east coast of peninsular Malaysia using a split-beam echo sounder. - Journal of Coastal Research $33(6)$.

[23] Hastie, T. J., Tibshirani, R. J. (1990): Generalized Additive Models. - Chapman and Hall, London, pp. 236-351. 
[24] He, Q., Zhan, H., Cai, S. et al. (2016): Eddy effects on surface chlorophyll in the northern South China Sea: mechanism investigation and temporal variability analysis. - Deep Sea Research Part I: Oceanographic Research Papers S0967063715301230.

[25] Hintze, J., Nelson, R. (1998): Violin plots: a box plot-density trace synergism. - The American Statistician 52(2): 4.

[26] Huang, M. Z. (1995): Feeding habits of Decafterus maruadsi in Taiwan Strait. - Journal of Applied of Oceanography (4): 399-406.

[27] Jaimes, E. J. (2017): 2. Capacidad de carga y presión de uso de la tierra en cuatro sectores de la sub-cuenca del río Déleg, Provincia del Cañar, Ecuador. - Revista de la Facultad de Agronomia de la Universidad del Zulia 34(3).

[28] Jamil, F., Arshad, R., Ali, M. A. (2018): Design, fabrication and evaluation of rotary hotair dryer for the value addition of fruit waste. - Earth Sciences Pakistan 2(2): 07-11.

[29] Jegatheesan, J., Zakaria, Z. (2018): Stress analysis on pressure vessel. - Environment \& Ecosystem Science 2(2): 53-57.

[30] Jiang, R. J., Xu, H. X., Jin, H. W., Zhou, Y. D., He, Z. T. (2012): Feeding habits of blue mackerel scad Decapterus maruadsi Temminck et Schlegel in the East China Sea. Journal of Fisheries of China 36(2): 216-227.

[31] Kang, L., Du, H. L., Zhang, H., Ma, W. L. (2018): Systematic research on the application of steel slag resources under the background of big data. - Complexity. doi.org/10.1155/2018/6703908.

[32] La Mesa, M., La Mesa, G., Catalano, B. et al. (2016): Spatial distribution pattern and physical-biological interactions in the larval notothenioid fish assemblages from the Bransfield Strait and adjacent waters. - Fisheries Oceanography 25(6): 624-636.

[33] Le, K., Yao, J. Z., Li, Z., Ke, Z. (2017): Preparation, characterization and photocatalytic activity of novel $\mathrm{CeO} 2$ loaded porous alkali-activated steel slag-based binding material. International Journal of Hydrogen Energy 42(27): 17341-17349.

[34] Li, X. D. (2006): Monthly variability in the catchability of chub macherel and round scad and its relationship with environmental seasonality in the southern Taiwan Strait. Xiamen University, Xiamen, pp. 40-72.

[35] Lu, Z. B., Dai, Q. S. (2000): An estimation of resources of chub mackerel, round scad and other pelagic fish stocks in the Taiwan Strait and the adjacent waters. - Journal of Fishery Sciences of China 7(1): 41-45.

[36] Maravelias, C. D., Reid, D. G. (1997): Identifying the effects of oceanographic features and zooplankton on prespawning herring abundance using generalized additive models. Marine Ecology Progress 147(1-3): 1-9.

[37] Nieto, K., Mélin, F. (2017): Variability of chlorophyll-a concentration in the Gulf of Guinea and its relation to physical oceanographic variables. - Progress in Oceanography 151: 97-115.

[38] Qu, Y. N., Pei, Z. B., Yang, S. T. (2018): Legal consideration on China's summer marine fishing moratorium system: in the perspective of venables sustainable development. Ocean Development and Management 9.

[39] Quinn, T. J., Deriso, R. B. (1999): Quantitative Fish Dynamic. - Oxford University Press, New York, pp. 124-256.

[40] Schütte, F., Brandt, P., Karstensen, J. (2016): Occurrence and characteristics of mesoscale eddies in the tropical northeast Atlantic Ocean. - Ocean Science 12(3): 663-685.

[41] Shih, C., Chen, Y., Hsu, C. (2014): Modeling the effect of environmental factors on the ricker stock-recruitment relationship for north pacific albacore using generalized additive models. - Terrestrial Atmospheric \& Oceanic Sciences 25: 581-590.

[42] Si, D., Liu, Y. J., Shao, X., Wang, Y. J. (2016): Anomalies of oceanic and atmospheric circulation in 2015 and their impacts on climate in China. - Meteorological Monthly 42(4): 481-488. 
[43] Solanki, H. U., Bhatpuria, D., Chauhan, P. (2017): Applications of generalized additive model (GAM) to satellite-derived variables and fishery data for prediction of fishery resources distributions in the Arabian Sea. - Geocarto International 32(1): 14.

[44] Song, X., Lai, Z., Ji, R., Chen, C., Zhang, J., Huang, L., Yin, J., Wang, Y., Lian, S. Zhu, X. (2012): Summertime primary production in northwest South China Sea: interaction of coastal eddy, upwelling and biological processes. - Continental Shelf Research 48(5): $110-121$.

[45] Stenseth, N. C., Mysterud, A., Ottersen, G. et al. (2002): Ecological effects of climate fluctuations. - Science 297(5585): 1292-1296.

[46] Stoner, A. W., Manderson, J. P., Pessutti, J. P. (2001): Spatially explicit analysis of estuarine habitat for juvenile winter flounder: combining generalized additive models and geographic information systems. - Marine Ecology Progress 213(4): 253-271.

[47] Sudhakaran, M., Ramamoorthy, D., Savitha, V., Balamurugan, S. (2018): Assessment of trace elements and its influence on physico-chemical and biological properties in coastal agroecosystem soil, Puducherry region. - Geology, Ecology, and Landscapes 2(3): 169176.

[48] Tao, S. (2018): Evaluation of technology innovation in Hubei Province. - Engineering Heritage Journal 2(2): 09-10.

[49] Thanh, L. D., Do, P. V. (2018): Streaming current induced by fluid flow in porous media. - Earth Sciences Malaysia 2(1): 22-28.

[50] Thomas, A. C., Strub, P. T., Weatherbee, R. A. et al. (2012): Satellite views of Pacific chlorophyll variability: comparisons to physical variability, local versus nonlocal influences and links to climate indices. - Deep Sea Research Part II Topical Studies in Oceanography 77-80(10): 99-116.

[51] Tianlei, W. (2019): Nonlinear control strategies and planning for underactuated overhead cranes. - Engineering Heritage Journal 3(1): 09-12.

[52] Tseng, C. T., Su, N. J., Sun, C. L. et al. (2013): Spatial and temporal variability of the Pacific saury (Cololabis saira) distribution in the northwestern Pacific Ocean. - Ices Journal of Marine Science 70(5): 991-999.

[53] Venables, W. N., Dichmont, C. M. (2004): GLMs, GAMs and GLMMs: an overview of theory for applications in fisheries research. - Fisheries Research 70(2-3): 315-333.

[54] Wang, J., Chen, X., Chen, Y. (2016): Spatio-temporal distribution of skipjack in relation to oceanographic conditions in the west-central Pacific Ocean. - International Journal of Remote Sensing 37(24): 6149-6164.

[55] Wang, X. X., Chen, T., Li, M., Wang, X. H., Wang, Y. Z. (2018): Relationships between environmental factors and the distribution of Indo-Pacific humpback dolphins (Sousa chinensis) in the western Pearl River Estuary, China. - Acta Ecologica Sinica 38(03): 934-944.

[56] Wang, Z., Li, Q., Sun, L. et al. (2015): The most typical shape of oceanic mesoscale eddies from global satellite sea level observations. - Frontiers of Earth Science 9(2): 202208.

[57] Wood, S. N. (2004): Stable and efficient multiple smoothing parameter estimation for generalized additive models. - J. Amer. Statist. Ass. 99: 673-686.

[58] Wood, S. N. (2011): Fast stable restricted maximum likelihood and marginal likelihood estimation of semiparametric generalized linear models. - Journal of the Royal Statistical Society (B) 73(1): 3-36.

[59] Wu, Z. Q., Qiu, S. Y., Yang, S. Y. (2000): Characters of reproductive biology of six pelagic fishes in Minnan-Taiwan bank fishing ground. - Marine Science Bulletin 19(2): $25-29$.

[60] Xie, L. L., Zong, X. L., Yin, X. F., Li, M. (2016): The interannual variation and longterm trend of Qiongdong Upwelling. - Oceanologia et Limnologia Sinica 47(1): 43-51. 
[61] Yan, L., Zhang, P., Yang, L., Yang, B. Z., Chen, S., Li, Y. N., Tan, Y. G. (2015): Effect of moon phase on fishing rate by light falling-net fishing vessels of Symplectoteuthis oualaniensis in the South China Sea. - South China Fisheries Science 3: 16-21.

[62] Yan, Y. M., Lu, Z. B., Dai, Q. S. (1987): Study on growth characteristics of round scad in Minzhong and Mindong fishing grounds. - Journal of Zoology 22(5): 8-13.

[63] Yang, L., Zhang, X. F., Tan, Y. G., Zhang, P. (2009): The catch composition of light falling-net fishing and its impact on fishery resources in the northern South China Sea. South China Fisheries Science 5(4): 41-46.

[64] Yang, L., Cao, W. Q., Lin, Y. S., Chen, Y. H., Lin, Z. J., Wang, X. H. (2016): Preliminary study on feeding habits and trophic niche of nine economic fish species in Beibu Gulf in summer. - Journal of Tropical Oceanography 35(2): 66-75.

[65] Yi, J., Du, Y., He, Z. et al. (2014): Enhancing the accuracy of automatic eddy detection and the capability of recognizing the multi-core structures from maps of sea level anomaly. - Ocean Science 10(1): 39-48.

[66] Yuan, Y., Liu, Y. J., Wang, Y. J., Wang, P. L. (2014): Main characteristics and possible causes for the climate in China during the spring of 2014. - Meteorological Monthly 41(10): 1292-1297.

[67] Zhan, P., Subramanian, A. C., Yao, F. et al. (2014): Eddies in the Red Sea: a statistical and dynamical study. - Journal of Geophysical Research Oceans 119(6): 3909-3925.

[68] Zheng, Y. J., Li, J. S., Zhang, Q. Y., Hong, W. S. (2014): Research progresses of resource biology of important marine pelagic food fishes in China. - Journal of Fisheries of China 38(1): 149-160.

[69] Zhu, D. L., Song, H. T., Bo, Z. L., Wu, Z. J. (1984): A study on mackerel and round scadfishing ground off Zhejiang coast in the summer-autumn season. - Marine Science Bulletin 3(2): 64-72.

[70] Zhu, Y. G. (2009): Research on the Effects of China's Summer Fishing Moratorium - A Perspective of Institutional Analysis. - Ocean University of China, Qingdao, pp. 89-95. 